\title{
-308 G/A TNF- $\alpha$ gene polymorphism influences the course of basal cell carcinoma in a Polish population
}

\author{
Michał Sobjanek ${ }^{1}$, Monika Zabłotna ${ }^{1}$, Igor Michajłowski ${ }^{1}$, Bogusław Nedoszytko ${ }^{1}$, \\ Aleksandra Lesiak ${ }^{2}$, Roman Nowicki ${ }^{1}$
}

${ }^{1}$ Department of Dermatology, Venerology and Allergology, Medical University
of Gdansk, Gdansk, Poland
${ }^{2}$ Department of Dermatology and Venerology, Medical University of Lodz, Lodz, Poland

Submitted: 20 August 2012

Accepted: 11 April 2013

Arch Med Sci 2015; 11, 3: 599-604

DOI: 10.5114/aoms.2015.52364

Copyright (@) 2015 Termedia \& Banach

\author{
Corresponding author: \\ Michał Sobjanek MD, PhD \\ Department of Dermatology, \\ Venerology and Allergology \\ Medical University of Gdansk \\ 7 Dębinki St \\ 80-211 Gdansk, Poland \\ Phone: +48583492580 \\ Fax: +48583492583 \\ E-mail: sobjanek@wp.pl
}

\begin{abstract}
Introduction: The etiopathogenesis of basal cell carcinoma (BCC) is multifactorial. The TNF- $\alpha$ gene seems to be an interesting gene candidate for BCC susceptibility because of the proinflammatory and immunosuppressive properties of its product. The aim of the study was to assess the frequency of $-308 \mathrm{G} / \mathrm{A}$ and $-238 \mathrm{G} / \mathrm{A}$ gene polymorphisms in the TNF- $\alpha$ gene and serum levels of cytokine in patients with BCC.

Material and methods: The study included 176 (94 women, 82 men) patients with BCC and 261 healthy volunteers. $-308 \mathrm{G} / \mathrm{A}$ and $-238 \mathrm{G} / \mathrm{A}$ TNF- $\alpha$ polymorphisms were analyzed using the amplification refractory mutation system-polymerase chain reaction method (ARMS-PCR). Serum concentrations of TNF- $\alpha$ were measured using ELISA.

Results: There was no statistically significant association between allele, genotype and haplotype frequencies in BCC patients in comparison with controls. Occurrence of the -308 TNF- $\alpha$ A allele or GA genotype in the group of patients with $B C C$ increases risk of recurrence of tumor recurrence $(O R=$ $4.8,95 \% \mathrm{Cl}: 1.6-13.9, p=0.004$ and $\mathrm{OR}=4.97,95 \% \mathrm{Cl}: 1.7-14.5, p=0.004)$. Moreover, -308 TNF- $\alpha$ GG genotype decreased risk of recurrence $(\mathrm{OR}=0.2$, $95 \% \mathrm{Cl}: 0.07-0.6, p=0.004)$. The $-238 /-308 \mathrm{GA}$ haplotype was connected with increased risk of recurrence $(\mathrm{OR}=4.36,95 \% \mathrm{Cl}: 1.49-12.7, p=0.007)$. We also found significantly higher TNF- $\alpha$ levels among BCC patients in comparison with controls $(p=0.004)$.

Conclusions: The obtained results did not confirm the role of the -308 $\mathrm{G} / \mathrm{A}$ and $-238 \mathrm{G} / \mathrm{A} T N F-\alpha$ gene polymorphisms in BCC development, but the presence of the A allele or GA genotype in -308 G/A TNF- $\alpha$ gene polymorphism may have an impact on the course of the disease.
\end{abstract}

Key words: tumor necrosis factor $\alpha, T N F-\alpha$, gene polymorphism, basal cell carcinoma, basal cell carcinoma.

\section{Introduction}

Basal cell carcinoma (BCC) is the most common cutaneous malignancy as well as the most common human malignancy overall, and its incidence is increasing. For more than 80 years, convincing epidemiological evidence has linked sun exposure with skin cancer. Basal cell carcino$\mathrm{ma}$ is more frequent in patients with higher cumulative sun exposure, with more sun-sensitive skin types, from areas of high ambient solar 
irradiance, and on sun-exposed body sites [1]. Apart from the direct mutagenic effect, ultraviolet radiation (UVR) plays an important role in photocarcinogenesis via immunosuppressive properties. To date, the pathogenic mechanisms of immunosuppressive UVR activity are not clearly elucidated. However, based on literature data one may conclude that impairment in tumor necrosis factor- $\alpha$ (TNF- $\alpha$ ) synthesis might play a crucial role in this process. It was shown that UVB exposure induces the release of TNF- $\alpha$ within the skin [2]. Tumor necrosis factor- $\alpha$ injection into mouse skin may provoke immunosuppressive effects similar to those induced by UVB exposure, and this phenomenon can be blocked by anti-TNF- $\alpha$ antibodies [3]. Tumor necrosis factor- $\alpha$ is one of the most important cytokines involved in the growth, differentiation, cellular function and survival of many cells, which plays a key role in the pathogenesis of many infections and inflammatory diseases. The TNF- $\alpha$ gene is located within the class III region of the human HLA locus, and several studies have shown extensive linkage disequilibrium both within the TNF locus and HLA class I and II. Several polymorphisms in the TNF- $\alpha$ gene have been found to be associated with various autoimmune disorders. Elevated levels of TNF- $\alpha$ mRNA and protein have been demonstrated in skin and sera of patients with autoimmune diseases. Tumor necrosis factor- $\alpha$ has also been reported to play an important role in the pathogenesis of cancer $[4,5]$.
The TNF- $\alpha$ gene is highly polymorphic, and many studies have shown associations between its functional polymorphic variants and an increased risk of developing tumors and inflammatory disorders $[5,6]$.

There are scarce and inconsistent data on the correlation between TNF- $\alpha$ gene polymorphisms and development of cutaneous malignancies.

In this study, two functional (-308 G/A and -238 $\mathrm{G} / \mathrm{A}$ ) single nucleotide polymorphisms in the promoter of the TNF- $\alpha$ gene were assessed in relation to the risk of BCC development in a northern Polish population. Moreover, we aimed to determine whether the presence of genetic disturbances influences the clinical course of BCC. Additionally, TNF- $\alpha$ serum level was measured and it was correlated with investigated $T N F-\alpha$ polymorphisms.

\section{Material and methods}

The study included 176 (94 women, 82 men) BCC patients at a mean age of $68.9 \pm 11.8$ years. All the patients were treated surgically during 2007-2009 in the Department of Dermatology, Venerology and Allergology, Medical University of Gdansk. None was an organ transplant recipient, was being treated with immunosuppressive drugs or suffered from any systemic inflammatory or other malignancy. Additionally, 261 healthy individuals, matched for age and sex, were enrolled to serve as controls (Table I). All subjects were exclusively of Eastern European/Polish descent.

Table I. Characteristics of the BCC patients investigated

\begin{tabular}{|lccc|}
\hline Variables & Males & Females & Overall group \\
\hline$N(\%)$ & $82(46.6)$ & $94(53.4)$ & 176 \\
\hline Age, mean \pm SD [years] & $69.6 \pm 9.9$ & $68.5 \pm 13.1$ & $68.9 \pm 11.8$ \\
\hline Age $<60$ years, $n(\%)$ & $13(37.1)$ & $22(62.9)$ & $35(22.6)$ \\
\hline Age $>60$ years, $n(\%)$ & $59(49.2)$ & $61(50.8)$ & $120(77.4)$ \\
\hline \begin{tabular}{l} 
Tumor size, $n(\%)[\mathrm{cm}]:$ \\
\hline 1
\end{tabular} & $27(35.1)$ & $50(64.9)$ & $77(48.4)$ \\
\hline$>1$ & $44(53.7)$ & $38(46.3)$ & $155(90.6)$ \\
\hline $\begin{array}{l}\text { Recognition, } n(\%): \\
\text { BCC }\end{array}$ & $71(45.8)$ & $84(54.2)$ & $16(9.4)$ \\
\hline BCC recurrent & $7(43.7)$ & $9(56.2)$ & $144(81.8)$ \\
\hline \begin{tabular}{l} 
Number of tumors, $n(\%):$ \\
\hline One tumor
\end{tabular} & $62(43.1)$ & $82(56.9)$ & $32(18.2)$ \\
\hline More than one tumor & $19(59.4)$ & $13(40.6)$ & $24(15.0)$ \\
\hline \begin{tabular}{l} 
Location, $n$ (\%): \\
\hline Area exposed to UV
\end{tabular} & $14(58.3)$ & $78(57.4)$ & $10(41.7)$ \\
\hline Area not exposed to UV & & & \\
\hline
\end{tabular}


The TNF- $\alpha$ gene polymorphisms at positions $-308 \mathrm{G} / \mathrm{A}$ and $-238 \mathrm{G} / \mathrm{A}$ were analyzed using the amplification refractory mutation system-polymerase chain reaction method (ARMS-PCR) according to the method described by Perrey et al. [7].

Serum concentrations of TNF- $\alpha$ were measured using the ELISA test in 74 BCC patients and 39 unaffected subjects.

\section{Statistical analysis}

The $\chi^{2}$ analysis was used to compare the observed number of genotypes with that expected for a population in a Hardy-Weinberg equilibrium. $\chi^{2}$ analysis was also used to test the significance of the differences of observed alleles and genotypes between groups. A logistic regression model was used to calculate the odds ratios (ORs) and 95\% confidence intervals (Cls). The Mann-Whitney $U$-test was used to compare the mean values, and the correlation was determined by mean Spearman coefficient values. Analyses were performed with Statistica 10 software (StatSoft, Inc. 2011). Value of $p<0.05$ was considered statistically significant. Haplotype estimation was conducted using the software package Phase v2.1 [8, 9].

\section{Results}

The genotype distribution of all polymorphisms was in Hardy-Weinberg equilibrium. Table II shows genotypes and alleles frequencies for TNF- $\alpha-308$ $\mathrm{G} / \mathrm{A}$ and $-238 \mathrm{G} / \mathrm{A}$ polymorphisms in patients with BCC and control subjects. There were no statistically significant association between allele, genotype and haplotype frequencies between BCC and control groups. However, AA genotype in $-308 \mathrm{G} / \mathrm{A}$ TNF- $\alpha$ polymorphisms was statistically more frequent in the group with multiple BCC compared to that with one tumor (3.13 vs. 0\%; $p=0.035)$. In the group of patients with recurrent BCC, GG genotype in -308 G/A TNF- $\alpha$ polymorphism was statistically less common than in the group without recurrence (43.75 vs. 78.81, $p=0.002$ ), whereas GA genotype was more frequent in the recurrent BCC group ( 56.25 vs. 20.53; $p=0.001)$. The presence of the $A$ allele or $\mathrm{GA}$ genotype for $-308 \mathrm{G} / \mathrm{A}$ TNF- $\alpha$ polymorphisms significantly increases $B C C$ recurrence risk $(O R=4.8$ (95\% Cl: 1.6-13.9), $p=0.004 ; \mathrm{OR}=4.97$ (95\% Cl: $1.7-14.5), p=0.004$, respectively). GG genotype in $-308 \mathrm{G} / \mathrm{A} T N F-\alpha$ polymorphism decreased that risk; $\mathrm{OR}=0.2$ (95\% Cl: 0.07-0.6; $p=0.004$ ) (Figures 1, 2).

The diplotype and haplotype frequencies were significantly different in the recurrent BCC group when compared to the non-recurrent BCC group ( $p=0.03 ; p=0.007)$. The $-238 /-308$ GA TNF- $\alpha$ haplotype was associated with increased risk of $\mathrm{BCC}$ recurrence; $\mathrm{OR}=4.36(95 \% \mathrm{Cl}: 1.49-12.7$; $p=0.007$ ) (Figures 3, 4).

We found a significantly increased TNF- $\alpha$ serum level among BCC patients in comparison with healthy controls (mean $0.173 \pm 0.076 \mathrm{pg} / \mathrm{ml}$; vs. $0.142 \pm 0.03 \mathrm{pg} / \mathrm{ml} ; p=0.004$ ) (Figure 5). A higher serum level was also observed in patients with tu-

Table II. Genotype and allele frequencies for $-308 \mathrm{G} / \mathrm{A}$ and $-238 \mathrm{G} / \mathrm{A}$ TNF polymorphisms in patients with BCC and control subjects

\begin{tabular}{|lccc|}
\hline Genotypes and alleles & Controls, $n(\%)$ & BCC, $n(\%)$ & Value of $p^{*}$ \\
\hline-308 & $n=261$ & $n=176$ & NS \\
\hline GG & $178(68.2)$ & $134(76.1)$ & NS \\
\hline GA & $80(30.7)$ & $41(23.3)$ & NS \\
\hline AA & $3(1.1)$ & $1(0.6)$ & \\
\hline & $n=522$ & $n=352$ & NS \\
\hline G & $436(83.5)$ & $309(87.8)$ & NS \\
\hline A & $86(16.5)$ & $43(12.2)$ & NS \\
\hline-238 & $n=261$ & $n=176$ & NS \\
\hline GG & $240(91.9)$ & $155(88.1)$ & NS \\
\hline GA & $21(8.1)$ & $21(11.9)$ & 0 \\
\hline AA & 0 & $n=352$ & $331(94)$ \\
\hline
\end{tabular}

$B C C-$ Basal cell carcinoma, NS - not significant. *Pearson's $\chi^{2}$. 


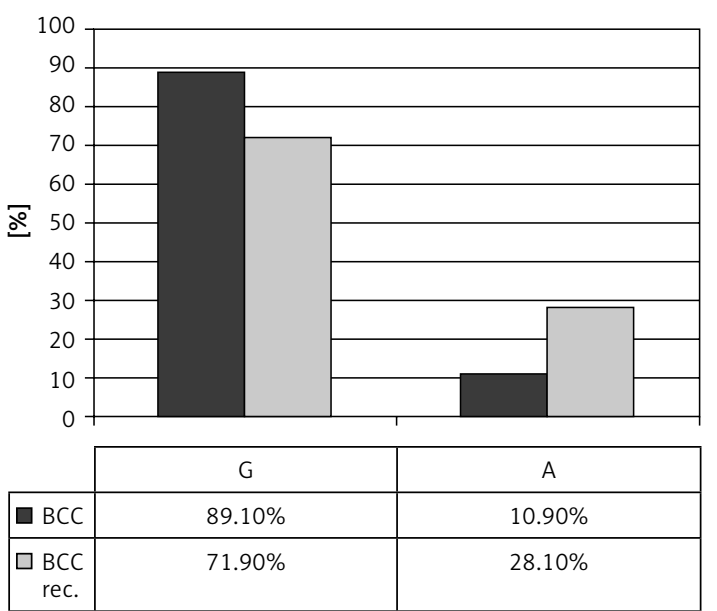

Figure 1. Allele frequencies of $-308 \mathrm{G} / \mathrm{A}$ TNF polymorphism in BCC patients with and without tumor recurrence $(p=0.005)$

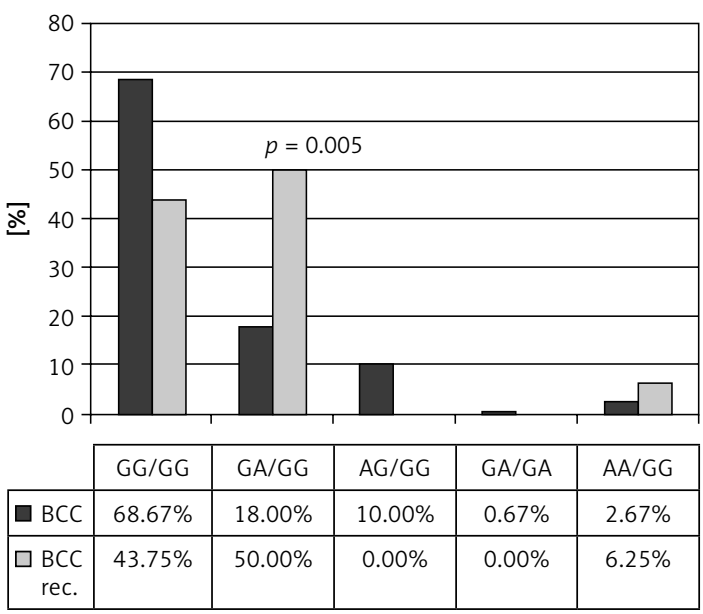

Figure 3. -238/-308 TNF diplotype frequencies in $B C C$ patients with and without tumor recurrence

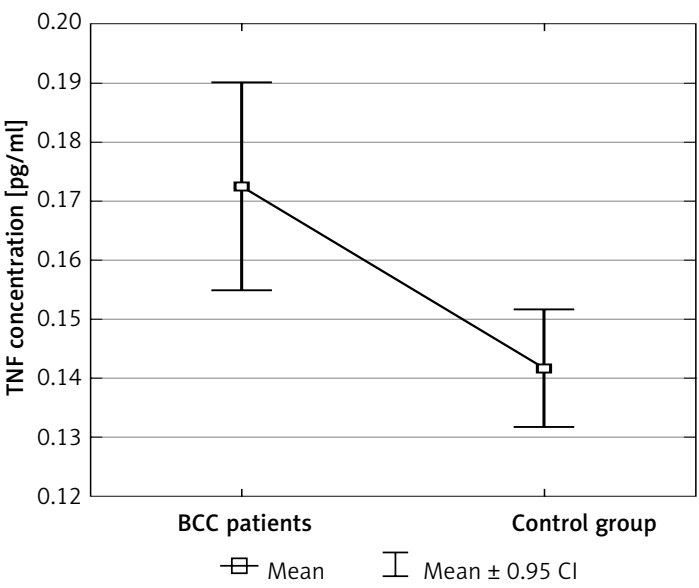

Figure 5. TNF- $\alpha$ serum level among BCC patients in comparison with healthy controls $(p=0.004)$

mors situated in sun-exposed areas compared to those on the trunk and extremities (mean 0.178 $\mathrm{pg} / \mathrm{ml}$ vs. $0.162 \mathrm{pg} / \mathrm{ml}$ ), but the difference was not statistically significant $(p=0.46)$. There were no correlations between TNF- $\alpha$ serum level and ex-

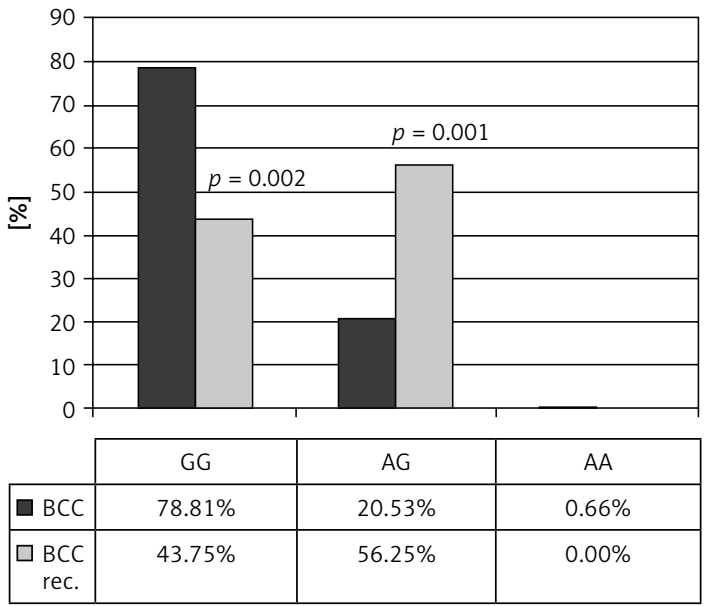

Figure 2. Genotype frequencies of $-308 \mathrm{G} / \mathrm{A}$ TNF polymorphism in BCC patients with and without tumor recurrence

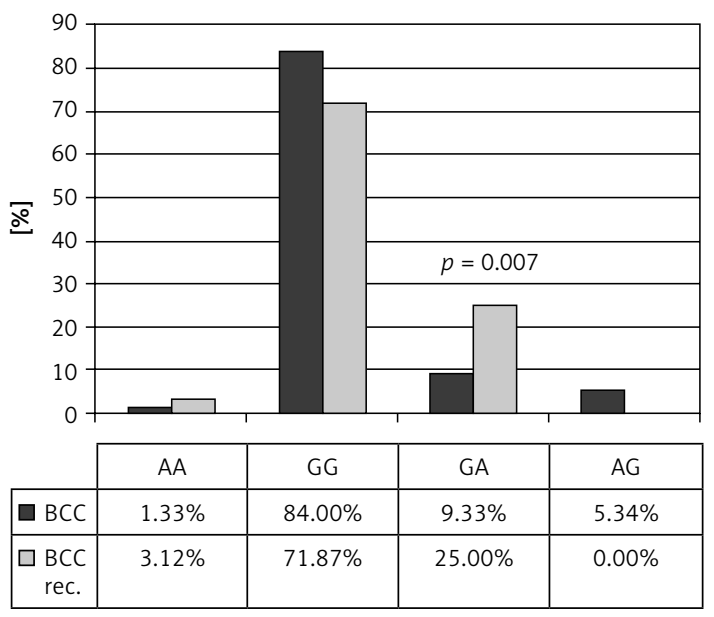

Figure 4. -238/-308 TNF haplotype frequencies in BCC patients with and without tumor recurrence

amined polymorphic variants of the TNF- $\alpha$ gene ( $p>0.05$ for all comparisons) (Table III).

\section{Discussion}

Ultraviolet radiation plays a crucial role in pathogenesis of non-melanoma skin cancer, including BCC. However, the significant number of tumors arising on non-sun-exposed areas of the skin suggests that other factors play a role in the pathogenesis of BCC. The association between $\mathrm{BCC}$ development and personal and family history of skin cancer is proven. The importance of immunosuppression in BCC etiopathogenesis was underlined by the increased risk of developing malignancy during immunosuppressive therapy [10].

Genetic studies in patients with BCC are focused on genes involved in DNA repair, defense against oxidative stress and others mutagens, immune modulation, tanning and other biochemical processes [11-14].

This study evaluated the potential impact of -308 G/A and -238 G/A TNF- $\alpha$ promoter gene poly- 
Table III. Mean serum levels of TNF for TNF genotypes

\begin{tabular}{|lcccccc|}
\hline Patients & \multicolumn{3}{c}{ TNF-238 } & \multicolumn{3}{c|}{ TNF-308 } \\
\cline { 2 - 7 } & GG & AG & AA & GG & AG & AA \\
\hline Control group & 0.141029 & 0.146000 & - & 0.143071 & 0.137200 & 0.147000 \\
$(n=39)$ & \pm 0.030770 & \pm 0.033941 & & \pm 0.033009 & \pm 0.026368 & \pm 0.000000 \\
\hline BCC patients & 0.170848 & 0.188857 & - & 0.172500 & 0.175846 & - \\
$(n=74)$ & \pm 0.076377 & \pm 0.080638 & & \pm 0.080720 & \pm 0.053074 & \\
\hline
\end{tabular}

morphisms on the development and clinical severity of BCC. These two polymorphisms are functional and can regulate cytokine production $[5,6]$.

$T N F-\alpha$ polymorphisms have been widely explored in several malignancies and inflammatory diseases, but there are only a few reports that have studied BCC patients $[5,15]$. The presence of -308 G/A TNF- $\alpha$ polymorphism was confirmed as a risk factor for development of many malignancies [5]. In contrast, $-238 \mathrm{G} / \mathrm{A}$ TNF- $\alpha$ polymorphism might play an apparently protective role against cancers, as reported by Jang et al. [16].

Our results are in line with Skov et al. [13], who did not find any association between -308 G/A TNF- $\alpha$ polymorphism and BCC development. Rizzato et al. [17] in their study conducted on 529 BCC cases from Central Europe found a link between 14 functional polymorphisms in 11 cytokine genes and BCC development. They reported that in the group of subjects more prone to skin burns, carriers of at last one copy of allele $G$ of the $-308 \mathrm{G} / \mathrm{A} T N F-\alpha$ gene polymorphism had an increased risk of BCC. A connection of the GG genotype and increased number of BCC was observed by Hajeer et al. [18]. In our study the presence of multiple BCCs was associated with AA genotype. Most important is the fact that GA genotype in $-308 \mathrm{G} / \mathrm{A}$ TNF- $\alpha$ polymorphisms is linked with five times higher risk of BCC recurrence while presence of GG genotype decreased that risk significantly. The diplotypes and haplotypes also had an influence on tumor recurrence. The -238/-308 GA TNF- $\alpha$ haplotype was associated with increased risk of BCC recurrence. This novel observation has not been previously described.

These results show that the recurrence tendency may be caused not only by some clinical and histopathological characteristics of the tumor but also by some genetic factors. Despite the suggested pivotal role of TNF- $\alpha$ in UV-induced immunosuppression, other cytokines are involved in determination of UV susceptibility. Welsh et al. [19] found that in men, a combination of skin type, burns, IL10, IL4R and possible TNFR2 polymorphisms was important in both BCC and squamous cell carcinoma (SCC) susceptibility. In women, skin type, burns and $I L-10$ were the most critical risk factors in SCC, with risk of BCC involving these same factors plus genetic variants in HTR2A. IL-12 b and IL-4r. Our unpublished data confirm the role of $-1082 \mathrm{G} / \mathrm{A} / \mathrm{L}-10$ polymorphism in BCC development in the Polish population. The role of $-238 \mathrm{G} / \mathrm{A} T N F-\alpha$ polymorphism is unclear and needs further investigations. These facts suggest that BCC presence is determined by the influence of environmental and genetic factors which interact with each other.

In our study we observed an increased TNF- $\alpha$ serum level in BCC patients. These results are consistent with Skov et al. [13], who demonstrated that BCC patients' mononuclear cells stimulated with lipopolysaccharide release significantly more TNF- $\alpha$ than control mononuclear cells. The increase in TNF- $\alpha$ level is related to poor prognosis in many malignancies [20, 21]. Elamin et al. [22] observed higher levels of TNF- $\alpha$, IL-4, and IL- 5 in tumors occurring on sun-exposed skin. In our report, we found a higher serum TNF- $\alpha$ level in patients with tumors occurring on sun-exposed skin, but the difference was not statistically significant. These results confirm that TNF- $\alpha$ plays a central role in immunosuppression induced by UVB and suggest their importance in UV-related BCC pathogenesis. The prognostic value of increased TNF- $\alpha$ level in BCC patients remains unclear. It may result from the need of homeostasis in human organisms and the activation of self-protective mechanisms. Cytokine is produced by tumor cells as well as activated immune cells, especially macrophages and T cells. The role of TNF- $\alpha$ in BCC etiopathogenesis seems to be complex. On the one hand, cytokine is involved in UV-related carcinogenesis, while on the other, it has anticarcinogenic functions. Recent investigations suggest that risk of skin cancer may be increased among patients treated with anti-TNF therapy [23].

In conclusion, the present results do not confirm the role of the $-308 \mathrm{G} / \mathrm{A}$ and $-238 \mathrm{G} / \mathrm{A} T N F-\alpha$ gene polymorphisms as predictor factors for BCC development in the Polish population. However, the presence of the $A$ allele or GA genotype in -308 G/A TNF- $\alpha$ gene polymorphism and the -238/-308 GA TNF- $\alpha$ haplotype may have an impact on the course of the disease. Further complex, multicenter investigations are strongly required.

\section{Conflict of interest}

The authors declare no conflict of interest. 


\section{References}

1. Lesiak A, Slowik-Rylska M, Rogowski-Tylman M, et al. Risk factors in Central Poland for the development of superficial and nodular basal cell carcinomas. Arch Med Sci 2010; 6: 270-5.

2. Skov L, Hansen $H$, Allen $M$, et al. Contrasting effects of ultraviolet $A 1$ and ultraviolet $B$ exposure on the induction of tumour necrosis factor-alpha in human skin. $\mathrm{Br}$ J Dermatol 1998; 138: 216-20.

3. Kurimoto I, Streilein JW. Cis-urocanic acid suppresion of contact hypersensivity induction is mediated via tumor necrosis-alpha. J Immunol 1992; 148: 3072-8.

4. Anderson GM, Nakada MT, DeWitte M. Tumor necrosis factor-alpha in the pathogenesis and treatment of cancer. Curr Opin Pharmacol 2004; 4: 314-20.

5. Zhou P, LV GQ, Wang JZ, et al. The TNF-alpha-238 polymorphism and cancer risk: a meta-analysis. PLoS One 2011; 6: e22092.

6. Nedoszytko B, Szczerkowska-Dobosz A, Zabłotna M, et al. Associations of promoter region polymorphisms in the tumour necrosis factor-alpha gene and early-onset psoriasis vulgaris in a northern Polish population. $\mathrm{Br}$ J Dermatol 2007; 157: 165-7.

7. Perrey C, Pravica V, Sinnott PJ, Hutchinson IV. Genotyping for polymorphisms in interferon-gamma, interleukin-10, transforming growth factor-beta 1 and tumour necrosis factor-alpha genes: a technical report. Transpl Immunol 1998; 6: 193-7.

8. Stephens M, Smith NJ, Donnelly P. A new statistical method for haplotype reconstruction from population data. Am J Hum Genet 2001; 68: 978-89.

9. Stephens M, Donnelly P. A comparison of bayesian methods for haplotype reconstruction. Am J Hum Genet 2003; 73: 1162-9.

10. Marcil I, Stern RS. Risk of developing a subsequant nonmelanoma skin cancer in a patients with history of the nonmelanoma skin cancer: a critical review of the literature and meta-analysis. Arch Dermatol 2000; 136: 1524-30.

11. Lesiak A, Norval M, Wodz-Naskiewicz K, et al. An enhanced risk of basal cell carcinoma is associated with particular polymorphisms in the VDR and MTHFR genes. Exp Dermatol 2011; 20: 800-4.

12. Sobjanek M, Zabłotna M, Michajłowski I, et al. Polymorphism of the vascular endothelial growth factor and susceptibility to basal cell carcinoma-preeliminary study. Postep Derm Alergol 2009; 26: 71-3.

13. Skov L, Allen MH, Bang B, et al. Basal cell carcinoma is associated with high TNF-alpha release but nor with TNF-alpha polymorphism at position -308. Exp Dermatol 2003; 12: 772-6.

14. Rizzato C, Scherer D, Rudnai P, et al. POMC and TP53 genetic variability and risk of basal cell carcinoma of skin: interaction between host and genetic factors. J Dermatol Sci 2011; 63: 47-54.

15. Szlosarek P, Charles KA, Balkwill FR. Tumour necrosis factor-alpha as a tumour promoter. Eur J Cancer 2006; 42: 745-50.

16. Jang WH, Yang YI, Yea SS, et al. The - 238 tumor necrosis factor-alpha promoter polymorphism is associated with decreased susceptibility to cancers. Cancer Lett 2011; 166: 41-6.

17. Rizzato C, Canzian F, Rudnai P, et al. Interaction between functional polymorphic variants in cytokine genes, established risk factors and susceptibility to basal cell carcinoma of skin. Carcinogenesis 2011; 32: 1849-54.
18. Hajeer AH, Lear JT, Ollier WE, et al. Preliminary evidence of an association of tumour necrosis factor microsatellites with increased risk of multiple basal cell carcinomas. Br J Dermatol 2000; 142: 441-5.

19. Welsh MM, Karagas MR, Kuriger JK, et al. Genetic determinants of UV-susceptibility in non-melanoma skin cancer. PLoS One 2011; 6: e20019.

20. Ocvirk J, Stabuc B, Rudolf Z, et al. Serum values of tumour necrosis factor-alpha and of soluble tumour necrosis factor-R55 in melanoma patients. Melanoma Res 2000; 10: 253-8.

21. Lu X, Qian CN, Mu YG, et al. Serum CCL2 and serum TNF-alpha: two new biomarkers predict bone invasion, post-treatment distant metastasis and poor overall survival in nasopharyngeal carcinoma. Eur J Cancer 2011; 47: 339-46.

22. Elamin I, Zecevic RD, Vojvodic D, Medenia L, Pavlovic D. Cytokine concentrations in basal cell carcinomas of different histological types and localisation. Acta Dermatoven APA 2008; 17: 55-9.

23. Mercer LK, Low AS, Galloway JB, et al. Anti-TNF therapy in women with rheumatoid arthritis with a history of carcinoma in situ of the cervix. Ann Rheum Dis 2013; 72: 143-4. 